\title{
Characteristics of Copper Coated Multi-Walled Carbon Nanotube Using Electroless Plating Process
}

\author{
I Dewa Made Pancarana ${ }^{1}$ \\ Department of Mechanical Engineering \\ Bali State Polytechnic \\ Bali, Indonesia \\ 1'dmpancarana@yahoo.com
}

\author{
Rudy Soenoko ${ }^{2}$, Djarot B. Darmadi ${ }^{3}$, Yudy Surya \\ Irawan ${ }^{4}$ \\ Department of Mechanical Engineering \\ Brawijaya University \\ Malang, Indonesia
}

\begin{abstract}
The copper coating process on multi-walled carbon nanotubes (MWCNT) has been carried out by electroless plating method to improve interfacial bonding between MWCNT and alumininium matrix. The initial step of electroless plating is to pre-treat MWCNT which includes oxidation (hydrophilic treatment), sensitization and activation. The oxidation process uses a solution of sulfuric acid and nitric acid, sensitization is carried out using tin (II) chloride dihydrate with hydrochloric acid, while the oxidation process uses a solution of palladium (II) chloride with hydrochloric acid. MWCNT which has been activated, is immersed in an electroless plating bath containing chemicals such as; Copper (II) sulfate pentahydrate, Potassium sodium tartrate tetrahydrate, Nickel (II) Chloride Hexahydrate, Polyethylene glycol 6000 and stirred with a magnetic stirrer at $200 \mathrm{rpm}$ temperature of $25^{\circ} \mathrm{C}$. Deposition time is varied, ie 15, 30 and 60 minutes.

Test results with SEM-EDX show that the deposition time affects the copper content of the MWCNT. With a deposition time of 15, 30 and 60 minutes, copper content was $1.141 \%, 3.227 \%$ and $33.56 \%$ by weight. The XRD test results showed that with 15 minutes deposition time, there was $97 \%$ MWCNT and $3 \%$ copper oxide compound. While cuprite compounds formed $61 \%$, $16 \%$ copper oxide compounds and $23 \%$ MWCNT at 30 minutes deposition time.
\end{abstract}

Keywords-- multi-walled carbon nanotubes, electroless plating, copper, deposition time.

\section{INTRODUCTION}

Carbon nanotubes are known to have unique structures and properties such as length to diameter ratio, strength, flexibility and high thermal conductivity, etc. [1-5]. Several studies have been conducted to obtain potential carbon nanotube applications. Lately, studies on carbon nanotubes have focused on hydrogen storage [6-8], catalyst [9], etc. which carbon nanotubes are used as a substitute for good performance. Further studies have been conducted focusing on metal deposite or metal oxide nanoparticles on the surface of carbon nanotubes [10-11]. Carbon nanotubes deposite with smaller particles and good space show better performance by increasing the active catalyst surface area and further demonstrating high chemical and thermal stability on carbon nanotubes. On the other hand, the electrical and mechanical properties of carbon nanotubes can be changed or adjusted through coating with metal nanoparticles to obtain the desired properties. Therefore, deposition on carbon nanotubes has made an important discussion in this study.

It is very difficult for most metals to deposite directly on the surface of carbon nanotubes. Therefore, a pre-treatment was carried out first to form functional groups such as carboxylic, carbonylic, and hydroxlic groups on the surface of carbon nanotubes preparing for metal nucleation or compounds. [12-13]. Characterization of carbon nanotubes revealed that the density of nanoparticles deposite on the surface of carbon nanotubes was low with this pre-treatment method. To increase the activity of carbon nanotube surfaces, Ang et al. [14], making the core catalytic with two-step sensitization-activation methods and a single-step activation approach. Activated carbon nanotubes are coated with copper and nickel with electroless plating methods. This pretreatment, is very complicated and in sensitization or activation, $\mathrm{SnCl}_{2}-2 \mathrm{H}_{2} \mathrm{O}$ used is harmful to people and the environment.

Carbon nanotubes have been added to various matrices to obtain carbon nanotube-reinforced composites [15]. To overcome the problem of wetting between carbon nanotubes and aluminum, the application of copper on the surface of carbon nanotubes is very effective. In the present study, carbon nanotubes were pre-treated with a simple purification and oxidation method, and by controlling the process parameters, a thick copper nanoparticle deposition on carbon nanotubes was obtained by electroless plating method.

\section{METHOD}

Multi Wall Carbon Nanotubes powder with size, OD: 10$20 \mathrm{~nm}$, length: 10-30 $\mu \mathrm{m}$ and purity $>98 \%$, purchased from supplier Chengdu Organic Chemicals Co. Ltd., China as the main ingredient in this study. The processing method used for MWCNT coating with $\mathrm{Cu}$ is the electroless plating method. MWCNT coating increases the strength of the sample and wettability with the matrix. The electroless plating process of MWCNT with $\mathrm{Cu}$ was carried out at the Lab. University of Brawijaya Chemical Engineering.

Before the electroless plating process, pre-treatment of MWCNT included oxidation (hydrophilic treatment), sensitization and activation. 
Oxidation: 1 gram MWCNT is mixed with $100 \mathrm{ml}$ of $\mathrm{H}_{2} \mathrm{SO}_{4}$ and $\mathrm{HNO}_{3}$ (1: 3) solution and maintained at $120^{\circ} \mathrm{C}$ for 10 hours (round magnetic stirrer at $100 \mathrm{rpm}$ ). MWCNT was rinsed with aquadest and separated from the media by centrifugation (centrifugation rotation at $4000 \mathrm{rpm}$ for 15 minutes).

Sensitization: The oxidized MWCNT is mixed with $250 \mathrm{ml}$ of a solution of $0.1 \mathrm{~mol} / \mathrm{L} \mathrm{SnCl}_{2} .2 \mathrm{H}_{2} \mathrm{O}-0.1 \mathrm{~mol} / \mathrm{L} \mathrm{HCl}$ for 30 minutes by rotating the magnetic stirrer at $100 \mathrm{rpm}$ at a temperature of $25^{\circ} \mathrm{C}$ (the solution was prepared beforehand and 72 hours at $25{ }^{\circ} \mathrm{C}$ ), followed by rinsing with distilled water and separated from the media by centrifugation (centrifugation rotation at $4000 \mathrm{rpm}$ for 15 minutes).

Activation: MWCNT which has been pre-activated / sensitized was mixed with $250 \mathrm{ml}$ solution of $0.0014 \mathrm{~mol} / \mathrm{L} \mathrm{PdCl}_{2}$ $0.25 \mathrm{~mol} / \mathrm{L} \mathrm{HCl}$ for 30 minutes by rotating the magnetic stirrer at $100 \mathrm{rpm}$ at a temperature of $25^{\circ} \mathrm{C}$, followed by rinsing with distilled water and separated from the media by centrifugation (centrifugation rotation at $4000 \mathrm{rpm}$ for 15 minutes).

Electroless plating: Activated MWCNT is inserted into an electroless plating tub which contains chemicals such as; Copper (II) pentahydrate sulfate $\left(\mathrm{CuSO}_{4} \cdot 5 \mathrm{H}_{2} \mathrm{O}\right)$, Potassium sodium tartrate tetrahydrate $\left(\mathrm{KNaC}_{4} \mathrm{H}_{4} \mathrm{O}_{6} \cdot 4 \mathrm{H}_{2} \mathrm{O}\right)$, Nickel (II) Chloride Hexahydrate $\left(\mathrm{NiCl}_{2} \cdot 6 \mathrm{H}_{2} \mathrm{O}\right)$, Polyethylene glycol 6000 . Volume of $250 \mathrm{ml}$ solution and stirred with magnetic stirrer at $100 \mathrm{rpm}$ temperature of $25{ }^{\circ} \mathrm{C}$ for 15,30 and 60 minutes, followed by the addition of Formaldehyde solution (HCHO) gradually. The $\mathrm{pH}$ of solution 12 is regulated by the addition of Sodium hydroxide $(\mathrm{NaOH})$. Furthermore MWCNT was washed and rinsed with aquadest and separated from the media by centrifugation (at $4000 \mathrm{rpm}$ for 15 minutes), then dried at $105^{\circ} \mathrm{C}$.

To find out the molecular groups of the MWCNT samples which were oxidized were analyzed using Fourier Transform Infrared (FTIR) Spectrometer with Shimadzu Prestige 21 brand in the Lab. Central Malang State University and the MWCNT sample which was coated by $\mathrm{Cu}$ were analyzed by microscopy using electron microscope (SEM) coupled with energy dispersive X-ray spectroscopy (EDX), at the Lab. Bio Science UB and Lab. Metallurgical Mechanical Engineering UNUD.

\section{RESULT AND DISCUSSION}

\section{A. Spectroscopic Analysis}

Based on the FTIR test results for pure MWCNT and oxidized MWCNT samples were analyzed using Fourier Transform Infrared (FTIR) Spectrometer of Shimadzu Prestige 21 brand in the Lab. Central Malang State University, obtained a graph as in Fig. 1.

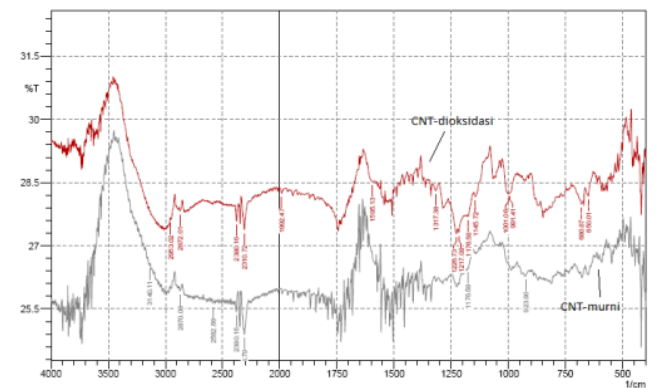

Fig. 1 . FTIR test results of pure MWCNT and MWCNT oxidized

From Fig. 1, it can be explained that;

- A peak appears at wave number $2850-2970 \mathrm{~cm}^{-1}$ which is likely to indicate the presence of $\mathrm{C}-\mathrm{H}$ Alkane groups which usually appear in wave numbers 2850-2970 and 1340-1470 $\mathrm{cm}^{-1}$.

- A peak appears at wave number $1300-1370 \mathrm{~cm}^{-1}$ which is likely to indicate the presence of $\mathrm{NO}_{2}$ group. Nitro compounds which usually appear in wave numbers 1500-1570 and 1300$1370 \mathrm{~cm}^{-1}$.

- The peak at wave number $1180-1360 \mathrm{~cm}^{-1}$ appears on the bacterial cellulose CMC sample which is likely to indicate the presence of a C-N Amine / amide group which usually appears in the wave number.

- A peak appears at the wave number $1050-1300 \mathrm{~cm}^{-1}$ which is likely to indicate the presence of a C-O alcohol group / ether / carboxylic acid / ester which usually appears in the wave number.

- A peak appears at wave numbers $690-900 \mathrm{~cm}^{-1}$ which is likely to indicate the presence of a $\mathrm{C}-\mathrm{H}$ group of aromatic rings which usually appear in wave numbers 690-900 and $3010-3100 \mathrm{~cm}^{-1}$.

- A peak appears at wave number $675-995 \mathrm{~cm}^{-1}$ which is likely to indicate the presence of an Alkena $\mathrm{C}-\mathrm{H}$ group which usually appears at wave numbers 675-995 and 3010-3095 $\mathrm{cm}^{-1}$.

\section{B. Microscopy Analysis}

The SEM test was first performed on pure MWCNT and oxidized MWCNT. What is done at the Lab. UB Bio Science and obtained the results as shown in Fig. 2 and Fig. 3. Next SEM-EDX test was carried out on the MWCNT sample which was $\mathrm{Cu}$-coated with a deposition time of 15 minutes. The results are shown in Fig. 4. The $\mathrm{Cu}$ content deposited in MWCNT was $1.141 \%$ by weight.

In Fig. 5 is the result of SEM-EDX test on the MWCNT sample which was coated by $\mathrm{Cu}$ with a deposition time of 30 minutes. The $\mathrm{Cu}$ content deposited in MWCNT was $3.227 \%$ by weight.

SEM-EDX test results Fig. 4 and 5 are carried out at UB's Science Lab. While the SEM-EDX test of the MWCNT sample which was $\mathrm{Cu}$ coated with 60 minutes deposition time, was carried out at the Lab. Mett Metallurgy Mechanical Engineering Unud. The results are shown in Fig. 6. The $\mathrm{Cu}$ content deposited on MWCNT is $33.56 \%$ by weight.

In the deposition process, the $\mathrm{Cu}$ particles from Copper (II) pentahydrate sulfate $\left(\mathrm{CuSO}_{4} \cdot 5 \mathrm{H}_{2} \mathrm{O}\right)$ which are in the solution move and attach to the surface of MWCNT. The 
longer the deposition time, the more $\mathrm{Cu}$ particles will stick to the surface of MWCNT.

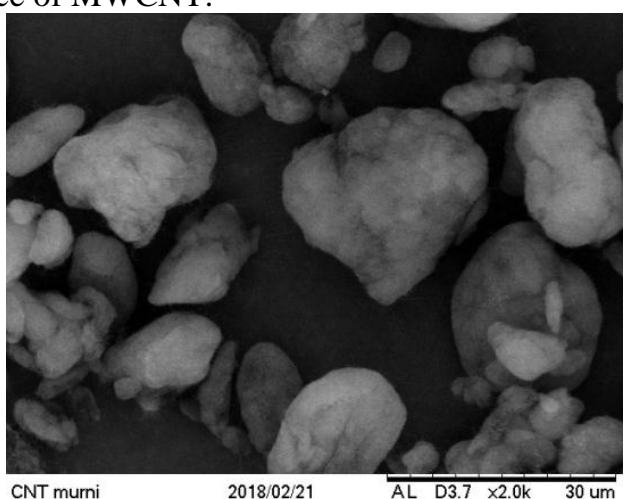

Fig. 2. SEM test results of pure MWCNT

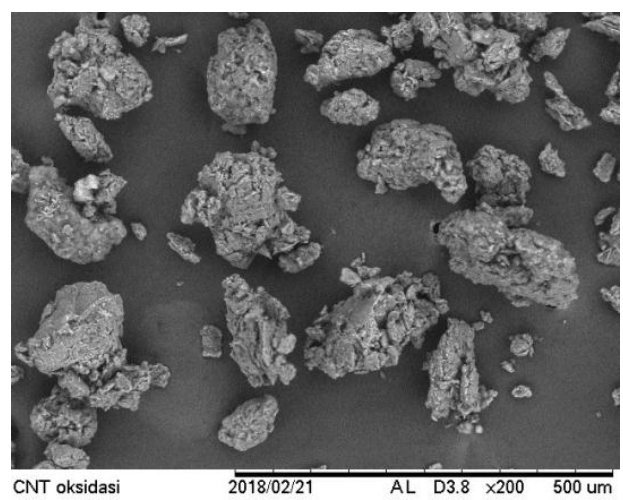

Fig. 3. SEM test results of MWCNT oxidized
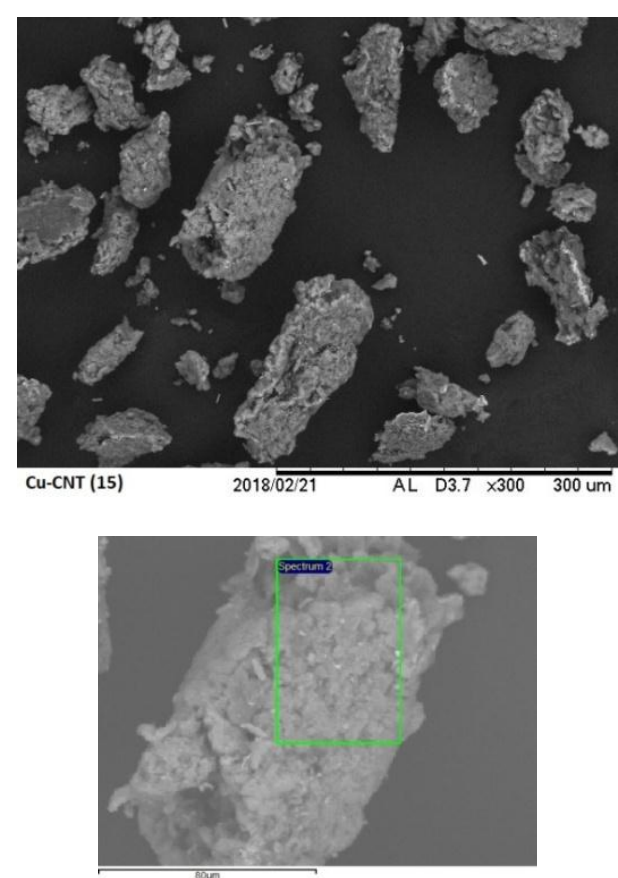

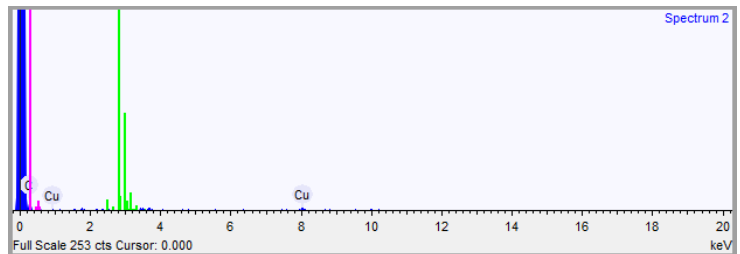

Fig. 4. SEM / EDX test results of MWCNT coated Cu with 15 minutes deposition time

TABLE I. COMPOSITION OF ELEMENTS IN MWCNT COATED CU WITH 15 MINUTES DEPOSITION TIME

\begin{tabular}{|l|l|l|l|}
\hline Element & Weight \% & Weight \% $~$ & Atomic \% \\
\hline Carbon & 98.859 & 1.107 & 99.782 \\
\hline Copper & 1.141 & 1.107 & 0.218 \\
\hline
\end{tabular}
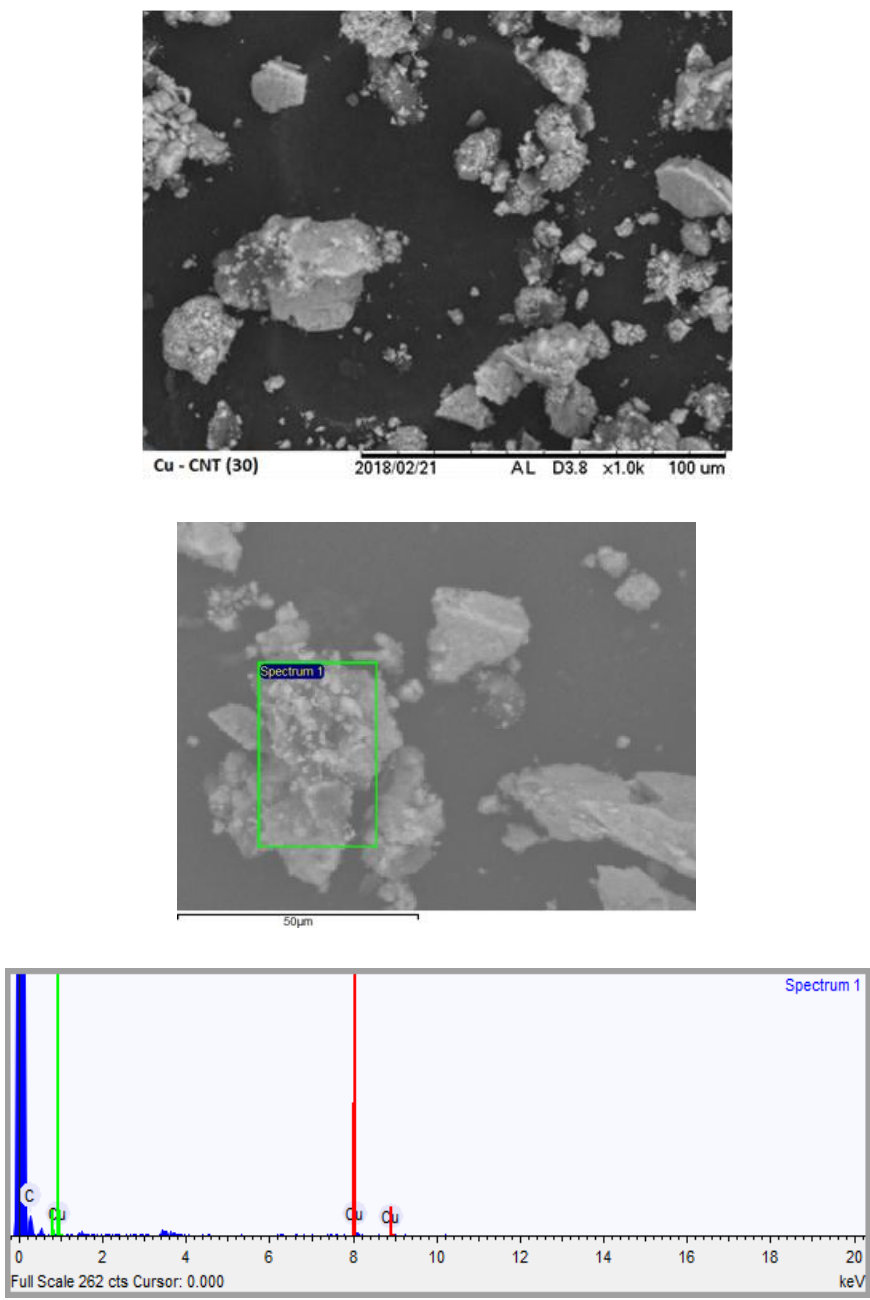

Fig. 5. SEM / EDX test results of MWCNT coated Cu with 30 minutes deposition time

TABLE II. COMPOSITION OF ELEMENTS IN MWCNT COATED CU WITH 30 MINUTES DEPOSITION TIME

\begin{tabular}{|l|l|l|l|}
\hline Element & Weight \% & Weight \% $~$ & Atomic \% \\
\hline Carbon & 96.773 & 1.860 & 99.374 \\
\hline Copper & 3.227 & 1.860 & 0.626 \\
\hline
\end{tabular}



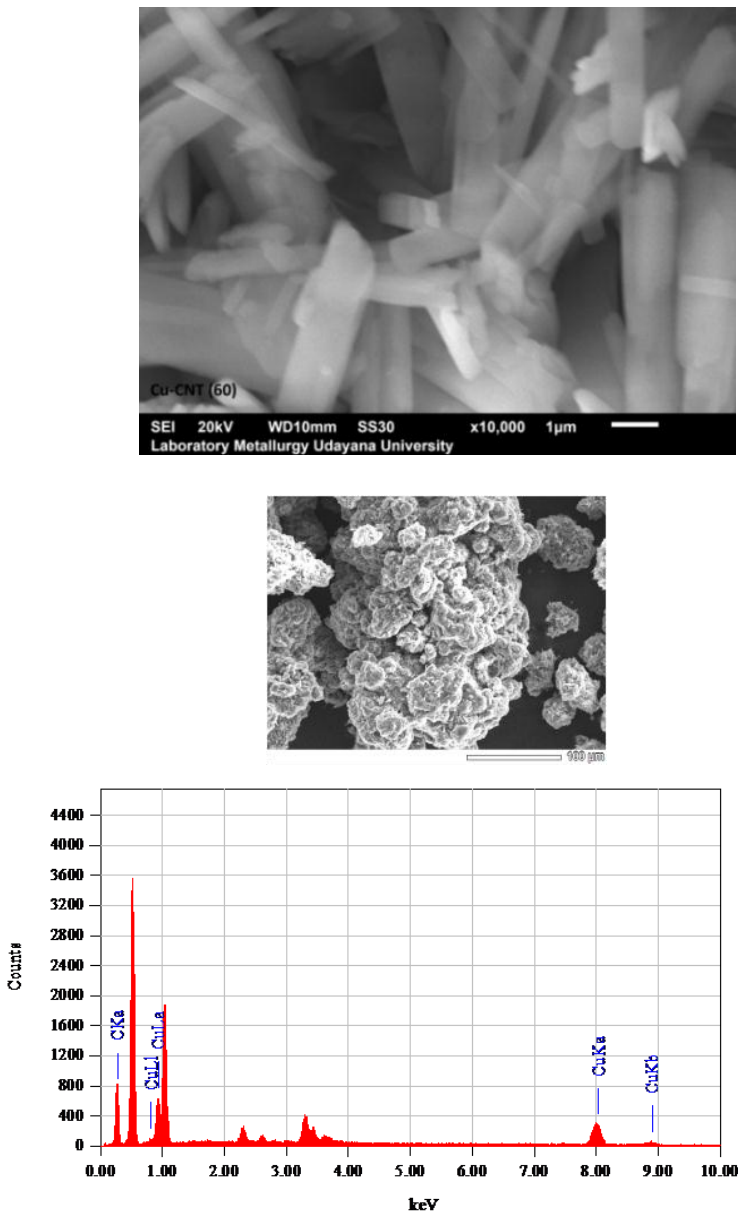

Fig. 6. SEM / EDX test results of MWCNT coated Cu with 60 minutes deposition time

TABLE III. COMPOSITION OF ELEMENTS IN MWCNT COATED CU WITH 60 MINUTES DEPOSITION TIME

\begin{tabular}{|c|c|c|c|c|c|}
\hline Element & $(\mathbf{k e V})$ & Mass\% & Sigma & Atom\% & K \\
\hline C K & 0.277 & 66.44 & 0.54 & 91.28 & 39.5256 \\
\hline Cu K & 8.040 & 33.56 & 0.77 & 8.72 & 60.4744 \\
\hline Total & & 100.00 & & 100.00 & \\
\hline
\end{tabular}

\section{XRD Analysis}

Based on data analysis using X'Pert HighScore software, the following data is obtained:
1). The pure MWCNT

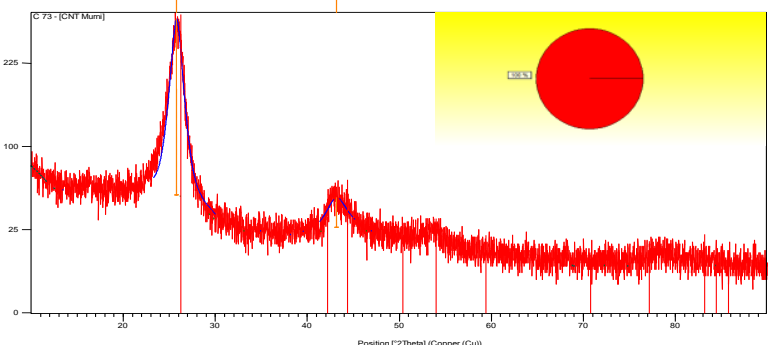

Fig. 7. Diffraction patterns of pure MWCNT from X'Pert HighScore analysis

HighScore X'Pert analysis results show that there is $100 \%$ content of C (Reference code: 01-075-1621). Identification of the plotted phase at start position $\left[{ }^{\circ} 2 \mathrm{Th}.\right]=10,0100$ and end position $\left[{ }^{\circ} 2 \mathrm{Th}.\right]=89,9900$, shown in Fig. 8 .

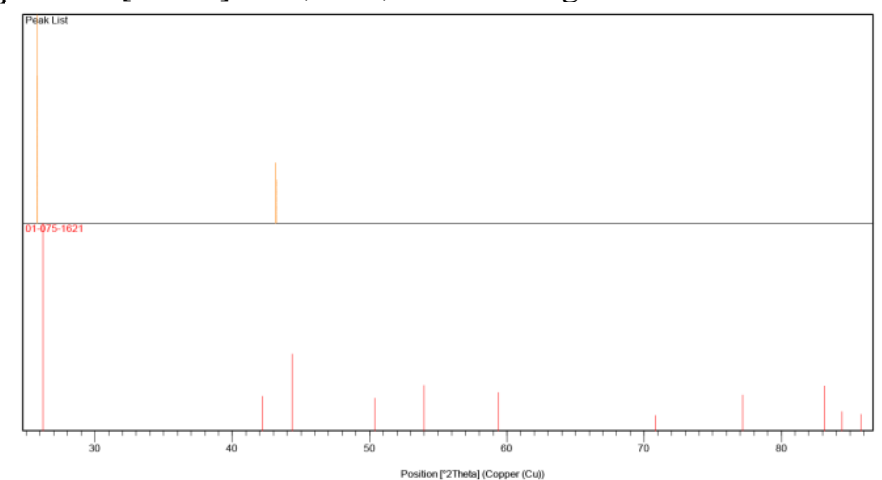

Fig. 8. Phase identification of pure MWCNT results from X'Pert HighScore analysis

2). The MWCNT coated $\mathrm{Cu}$ with 15 minutes deposition time

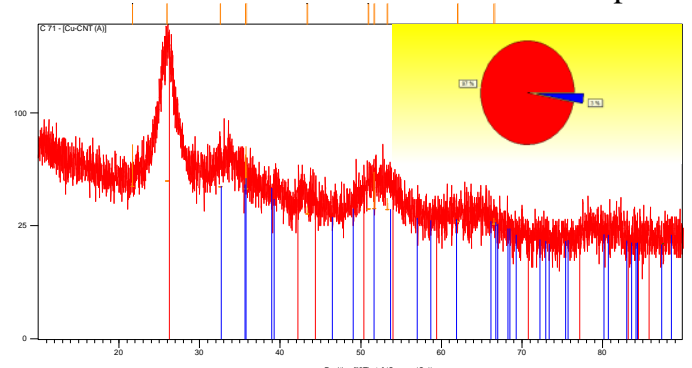

Fig. 9. Diffraction pattern of MWCNT coated $\mathrm{Cu}$ with 15 minutes deposition time results from $\mathrm{X}^{\prime}$ Pert High Score analysis

TABLE IV. DIFFRACTION PEAKS OF PURE MWCNT

\begin{tabular}{|c|c|c|c|c|c|c|}
\hline Pos. $\left[{ }^{\circ} \mathbf{2}\right.$ Th.] & Height [cts] & FWHM [ ${ }^{\circ}$ Th.] & d-spacing [̊] & Rel. Int. [\%] & Tip width [ ${ }^{\circ}$ 2Th.] & Matched by \\
\hline 25.7737 & 260.96 & 1.6371 & 3.45385 & 100.00 & 1.9645 \\
\hline 25.8389 & 130.48 & 1.6371 & 3.45385 & 50.00 & $01-075-1621$ \\
\hline 43.1387 & 22.33 & 2.4951 & 2.09533 & 8.56 & 1.9645 \\
\hline 43.2513 & 11.17 & 2.4951 & 2.09533 & 4.28 & 2.9941 & $01-075-1621$ \\
\hline
\end{tabular}

HighScore X'Pert analysis results show that there are $97 \%$ C (Reference code: 01-075-1621) and 3\% CuO / Copper Oxide content (Reference code: 01-074-1021). Identification of the phase is plotted at start position $\left[{ }^{\circ} 2 \mathrm{Th}.\right]=10,0100$ and end position $\left[{ }^{\circ}\right.$ 2Th.] $=89,9900$, shown in Fig. 10 . 


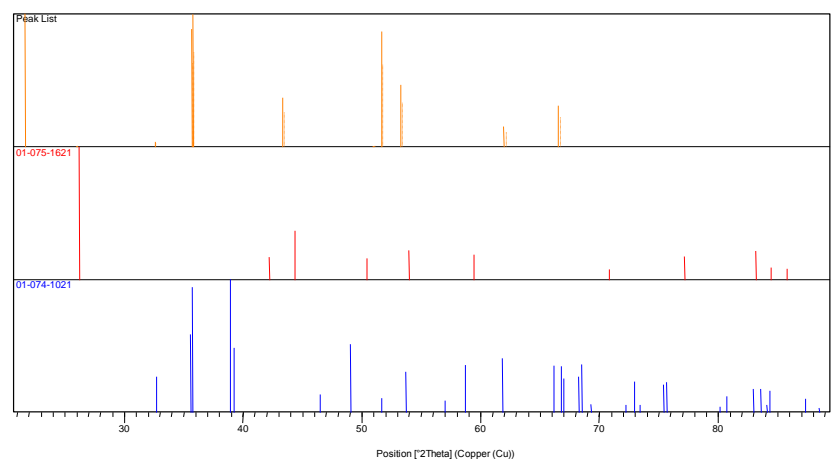

Fig. 10. Phase identification of MWCNT coated $\mathrm{Cu}$ with 15 minutes deposition time results from X'Pert HighScore analysis

TABLE V. DIFFRACTION PEAKS OF MWCNT COATED CU WITH 15 MINUTES DEPOSITION TIME

\begin{tabular}{|c|c|c|c|c|c|c|}
\hline Pos. $\left[{ }^{\circ}\right.$ 2Th. $]$ & Height [cts] & FWHM [ ${ }^{\circ}$ Th. $]$ & d-spacing $[\AA]$ & $\begin{array}{c}\text { Rel. Int. } \\
{[\%]}\end{array}$ & $\begin{array}{c}\text { Tip width } \\
{\left[{ }^{\circ} 2 \text { Th. }\right]}\end{array}$ & Matched by \\
\hline 21.6857 & 28.53 & 0.1055 & 4.09821 & 100.00 & 0.1265 & \\
\hline 25.9700 & 0.00 & 4.0000 & 3.42818 & 0.00 & 4.8000 & 01-075-1621 \\
\hline 26.0357 & 0.00 & 4.0000 & 3.42818 & 0.00 & 4.8000 & \\
\hline 32.5700 & 0.04 & 0.0010 & 2.74699 & 0.15 & 0.0012 & 01-074-1021 \\
\hline 32.6532 & 0.02 & 0.0010 & 2.74699 & 0.07 & 0.0012 & \\
\hline 35.6744 & 22.44 & 0.4299 & 2.51474 & 78.66 & 0.5159 & 01-074-1021 \\
\hline 35.7660 & 11.22 & 0.4299 & 2.51474 & 39.33 & 0.5159 & \\
\hline 35.7781 & 28.44 & 0.0593 & 2.50769 & 99.70 & 0.0711 & 01-074-1021 \\
\hline 35.8700 & 14.22 & 0.0593 & 2.50769 & 49.85 & 0.0711 & \\
\hline 43.3300 & 3.90 & 0.0900 & 2.08652 & 13.67 & 0.1080 & \\
\hline 43.4431 & 1.95 & 0.0900 & 2.08652 & 6.83 & 0.1080 & \\
\hline 50.9300 & 0.00 & 0.0010 & 1.79156 & 0.00 & 0.0012 & \\
\hline 51.0656 & 0.00 & 0.0010 & 1.79156 & 0.00 & 0.0012 & \\
\hline 51.6280 & 21.53 & 0.0687 & 1.76897 & 75.46 & 0.0825 & 01-074-1021 \\
\hline 51.7657 & 10.76 & 0.0687 & 1.76897 & 37.73 & 0.0825 & \\
\hline 53.2500 & 6.23 & 0.0900 & 1.71885 & 21.85 & 0.1080 & 01-074-1021 \\
\hline 53.3928 & 3.12 & 0.0900 & 1.71885 & 10.92 & 0.1080 & \\
\hline 61.9700 & 0.66 & 0.0900 & 1.49627 & 2.32 & 0.1080 & 01-074-1021 \\
\hline 62.1411 & 0.33 & 0.0900 & 1.49627 & 1.16 & 0.1080 & \\
\hline 66.5300 & 2.72 & 0.0900 & 1.40434 & 9.55 & 0.1080 & 01-074-1021 \\
\hline 66.7169 & 1.36 & 0.0900 & 1.40434 & 4.78 & 0.1080 & \\
\hline
\end{tabular}

3). The MWCNT coated $\mathrm{Cu}$ with 30 minutes deposition time

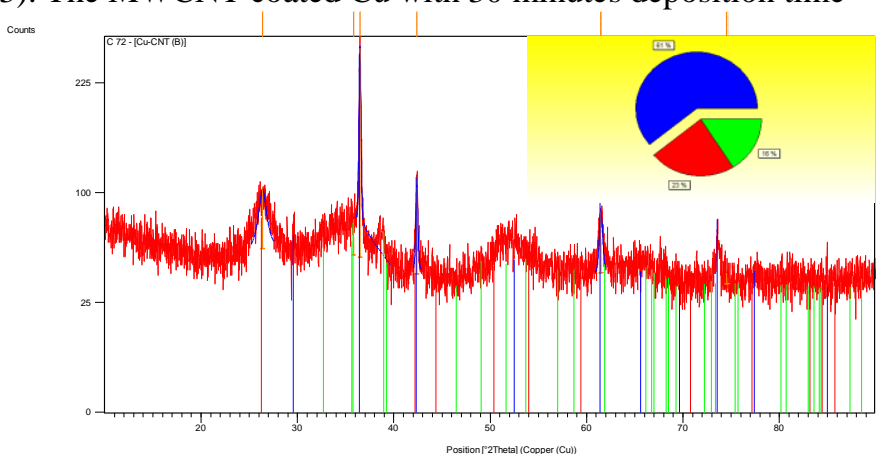

Fig. 11. Diffraction pattern of MWCNT coated Cu with 30 minute deposition time results from X'Pert HighScore analysis

HighScore $X^{\prime}$ Pert analysis results show that there is a content of C (Reference code: 01-075-1621) of 21\%, $\mathrm{CuO} /$ Copper Oxide (Reference code: 01-074-1021) of 16\% and $\mathrm{Cu} 2 \mathrm{O} /$ Cuprite (Reference code: 01 -078-2076) $61 \%$. Identification of the plotted phase at start position [ ${ }^{\circ} 2 \mathrm{Th}$. $]=$
10,0100 and end position $\left[{ }^{\circ}\right.$ 2Th.] $=89,9900$, shown in Fig. 11.

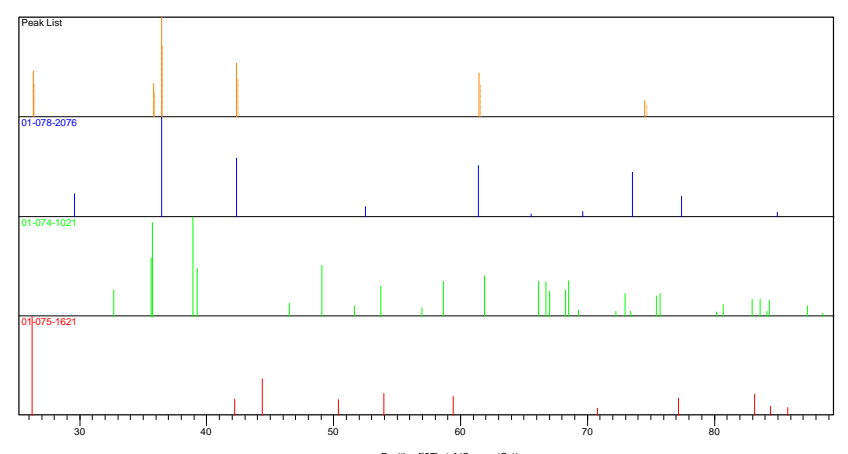

Fig. 12. Phase identification of MWCNT coated $\mathrm{Cu}$ with 30 minutes deposition time results from $X^{\prime}$ Pert HighScore analysis 
TABLE VI. DIFFRACTION PEAKS OF MWCNT COATED CU WITH 30 MINUTES DEPOSITION TIME

\begin{tabular}{|c|c|c|c|c|c|c|}
\hline Pos. $\left[{ }^{\circ}\right.$ 2Th. $]$ & Height [cts] & FWHM [ $\left.{ }^{\circ} 2 \mathrm{Th}.\right]$ & d-spacing $[\AA]$ & Rel. Int. [\%] & Tip width [ $\left.{ }^{\circ} 2 \mathrm{Th}.\right]$ & Matched by \\
\hline 26.3528 & 47.32 & 0.9567 & 3.37925 & 21.11 & 1.1480 & $01-075-1621$ \\
\hline 26.4195 & 23.66 & 0.9567 & 3.37925 & 10.55 & 1.1480 & \\
\hline 35.8118 & 25.87 & 4.0000 & 2.50540 & 11.54 & 4.8000 & $\begin{array}{l}01-078-2076 ; \\
01-074-1021\end{array}$ \\
\hline 35.9039 & 12.93 & 4.0000 & 2.50540 & 5.77 & 4.8000 & \\
\hline 36.4662 & 224.19 & 0.1695 & 2.46194 & 100.00 & 0.2034 & $\begin{array}{l}01-078-2076 ; \\
01-074-1021\end{array}$ \\
\hline 36.5600 & 112.10 & 0.1695 & 2.46194 & 50.00 & 0.2034 & \\
\hline 42.3570 & 66.02 & 0.2010 & 2.13217 & 29.45 & 0.2412 & $\begin{array}{l}01-078-2076 ; \\
01-075-1621\end{array}$ \\
\hline 42.4674 & 33.01 & 0.2010 & 2.13217 & 14.72 & 0.2412 & \\
\hline 61.4336 & 43.32 & 0.3798 & 1.50804 & 19.32 & 0.4557 & $\begin{array}{l}01-078-2076 ; \\
01-074-1021\end{array}$ \\
\hline 61.6029 & 21.66 & 0.3798 & 1.50804 & 9.66 & 0.4557 & \\
\hline 74.4965 & 6.13 & 4.0000 & 1.27265 & 2.74 & 4.8000 & $\begin{array}{l}01-078-2076 ; \\
01-074-1021\end{array}$ \\
\hline 74.7131 & 3.07 & 4.0000 & 1.27265 & 1.37 & 4.8000 & \\
\hline
\end{tabular}

\section{CONCLUSIONS}

In the MWCNT coating process with $\mathrm{Cu}$ using electroless plating method, with varying deposition times, it shows that increasing deposition time causes the $\mathrm{Cu}$ content in MWCNT to increase. From the experimental results, it was found that copper content was $1.141 \%, 3.227 \%$ and $33.56 \%$ by weight in MWMWCNT for 15, 30, and 60 minutes deposition time.

The XRD test results showed that with 15 minutes deposition time, there was $97 \%$ MWCNT and $3 \%$ copper oxide compound. While cuprite compounds formed $61 \%, 16$ $\%$ copper oxide compounds and $23 \%$ MWCNT at 30 minutes deposition time.

\section{ACKNOWLEDGMENT}

The author would like to thank the Ministry of Technology Research and the Higher Education of Republic of Indonesia for financial support through the scheme of the Doctoral Dissertation Research Grant in the 2018 fiscal year.

\section{REFERENCES}

[1] S. Iijima, C. Brabec, A. Maiti, J. Bernholc, "Structural flexibility of carbon nanotubes," J. Chem. Phys., Vol. 104 No. 5, pp. 2089-2092, 1996.

[2] R. Saito, M. Fujita, G. Dresselhaus, M.S. Dresselhaus, "Electronic structure of chiral graphene tubules," Appl. Phys. Lett. Vol. 60 No. 18, pp. 2204-2206, 1992.

[3] R.S. Ruoff, D.C. Lorents, "Mechanical and thermal properties of carbon nanotubes," Carbon, vol. 33 No. 7, pp. 925-930, 1995.
[4] M.M.J. Treacy, T.W. Ebbesen, J.M. Gibson, "Exceptionally high Young's modulus_observed for individual carbon nanotubes," Nature, Vol. 381 No. 6584, pp. 678-680, 1996.

[5] T.W. Ebbesen, "Wetting, filling and decorating carbon nanotubes," J. Phys. Chem. Solids, Vol. 57 No. 6-8, pp. 951-955, 1996.

[6] A.C. Dillon, K.M. Jones, T.A. Bekkedahl, C.H. Kiang, D.S. Bethune, M.J. Heben, "Storage of hydrogen in single-walled carbon nanotubes," Nature Vol. 386 No. 6623, pp. 377-379, 1997.

[7] A.Y. Cao, H.W. Zhu, X.F. Zhang, X.S. Li, D.B. Ruan, C.L. Xu, B.Q.Wei, J. Liang, D.H. Wu, "Hydrogen storage of dense-aligned carbon nanotubes," Chem. Phys. Lett., Vol. 342 No. 5-6, pp. 510-514, 2001.

[8] C. Liu, Y.Y. Fan, M. Liu, H.T. Cong, H. M Cheng, M.S. Dresselhaus, Hydrogen storage in single-walled carbon nanotubes at room temperature, Science 286 (5442) (1999) 1127-1129.

[9] J.F. Chen, C.L. Xu, Z.Q. Mao, G.R. Chen, B.Q. Wei, J. Liang, D.H. Wu, "Study of Electroless Ni-P-CNTs Composite Plating," Sci. Chin. Ser. A Vol. 45 No. 1, pp. 82-86, 2002.

[10] Y. Zhang, N.W. Franklin, R.J. Chen, H.J. Dai, "Metal coating on suspended carbon nanotubes and its implication to metal-tube interaction," Chem. Phys. Lett., Vol. 331 No. 1, pp. 35-41, 2000.

[11] K. Ota, A. Kawabata, H. Murakami, E. Kita, "Nano-Metals I. Metal Nanocrystals Grown by Vacuum Deposition on Aligned Carbon Nanotubes.", Mater. Trans., Vol. 42 No. 8, pp. 1684-1687, 2001.

.[12] T.W. Ebbesen, H. Hiura, M.E. Bischer, "Electrical conductivity of individual carbon nanotubes,” Adv. Mater. Vol. 8 No. 2, pp. 155, 1996.

[13] B.C. Satishkumar, E.M. Vogl, A. Govindaraj, C.N.R. Rao, "The decoration of carbon nanotubes by metal nanoparticles," J. Phys. D: Appl. Phys., vol. 29 No. 12, pp. 3173-3176, 1996.

[14] L.M. Ang, T.S.A. Hor, G.Q. Xu, C.H. Tung, S.P. Zhao, J.L.S. Wang, "Decoration of activated carbon nanotubes with copper and nickel," Carbon, Vol. 38 No. 3, pp. 363-372, 2000.

[15] C.L. Xu, B.Q. Wei, R.Z. Ma, J. Liang, X.K. Ma, D.H. Wu, "Fabrication of aluminum-carbon nanotube composites and their electrical properties," Carbon, vol. 37 No. 5, pp. 855-858, 1999. 